\title{
A festa das letras: uma alfabetização possível
}

\section{The party of letters: a possible literacy}

DOI: $10.46814 /$ lajdv2n5-003

Recebimento dos originais: 10/07/2020

Aceitação para publicação: 30/08/2020

\section{Neli Aparecida Gai Pereira}

Doutora em Educação pela Universidade do Vale do Rio dos Sinos; Professora Titular da Universidade do Oeste de Santa Catarina - Unoesc Xanxerê

Endereço: Rua das violetas, 274, bairro Di Fiori. Guatambu, Santa Catarina, Brasil.

E-mail: neli.gai@unoesc.edu.br

\section{Sandy Carla Fernandes de Queiróz}

Especialista em Concepções Multidisciplinares de Leitura pelo Instituto Federal de Santa Catarina IFSC/ Xanxerê

Endereço: R. Euclides Hack, 1603 - Veneza, Xanxerê - SC, 89820-000.

E-mail: sandy-carla@hotmail.com

\section{RESUMO}

O presente estudo discute como a Festa das Letras pode auxiliar no processo de formação docente, assim como, no processo de alfaletrar e de aprendizagem. Com o objetivo de formar alfabetizadores críticos e preparados para atuar na Educação Básica, a Universidade do Oeste de Santa Catarina possibilita aos acadêmicos uma formação de qualidade. O curso de Pedagogia desenvolve, na disciplina de Alfabetização e Letramento II, uma nova estratégia para que as crianças aprendam a ler e escrever de forma lúdica, de cunho sistematizado e científico, intitulado "Festa das Letras". A Festa das Letras apresenta metodologias diferenciadas para o processo de alfaletrar, dentre elas: rimas, história da escrita, história do alfabeto, canto, além de um ambiente alfabetizador. A sistemática foi desenvolvida com vários grupos de crianças, com idade entre 05 e 09 anos. A Festa das Letras pode ser utilizada na alfabetização e letramento com crianças de todos os lugares, além de auxiliar na apropriação do processo de leitura e escrita, fatores indispensáveis para o desenvolvimento cognitivo e social das crianças.

Palavras-chaves: Festa das Letras, Alfaletrar, Ludicidade.

\begin{abstract}
The present study discusses how the Party of Letters can help in the process of teacher training, as well as in the process of alphalbeting and learning. Aiming to train critical literacy teachers and prepared to work in Basic Education, the University of the West of Santa Catarina provides students with quality training. The Pedagogy course develops, in the Literacy and Literacy II subject, a new strategy for children to learn how to read and write in a playful way, of a systematic and scientific nature, entitled "Party of Letters". The Party of Letters presents different methodologies for the alphabetic process, among them: rhymes, history of writing, history of the alphabet, singing, in addition to a literacy environment. The system was developed with several groups of children, aged between 05 and 09 years old. The Party of Letters can be used in literacy with children everywhere, besides assisting in the appropriation of the reading and writing process, which are indispensable factors for children's cognitive and social development.
\end{abstract}


Key words: Party of letters, Alphabeting, Playfulness.

\section{INTRODUÇÃO}

Nestas palavras introdutórias da metodologia, intitulada, Festa das letras, explicitamos o desejo e a necessidade de pensar a alfabetização e o letramento como centro de acolhimento cognitivo, pois ao tempo em que se deixa de dedicar ao ensino e à aprendizagem para dedicar-se somente às questões sociais, podemos deixar de aprender.

Este projeto implantado no Campus de Xanxerê desde 2011, no curso de Pedagogia na disciplina de Alfabetização e Letramento, implantou uma nova estratégia para que as crianças aprendam a ler e escrever de forma lúdica, dentro de um cunho sistematizado e científico, denominado, "Festa das Letras".

Diante disso, nasce o desejo de investigar como a festa das letras pode auxiliar no processo de formação alfabetizador letrador.

Por meio de uma concepção dialética, desenvolve-se uma proposta teórica-metodológica de alfabetizar letrando. O estudo pensa como a Festa das Letras pode auxiliar na formação das alfabetizadoras, no desenvolvimento da metodologia, pois acreditamos que a primeira condição da inclusão social é a inclusão cognitiva.

A possível resposta dessa interrogativa está entre a vasta produção em relação à alfabetização e o letramento, os métodos de alfabetização, a leitura, a escrita, os níveis da escrita e as práticas sociais, os chavões da alfabetização cidadã, libertadora e emancipatória. Em verdade, propomo-nos a compreender a função da alfabetização e do letramento na experiência a ser pesquisada focada nas questões sociais e tornar esta, uma pesquisa que possa contribuir com a formação dos alfabetizadores letradores que asseguram o sucesso da aprendizagem.

Essa tarefa não está sendo fácil; ao contrário, é muito desafiadora por vários motivos, dos quais destacamos três, que provocam de forma mais veemente: querer, fazer e viver uma metodologia. É uma tarefa provocadora: primeiro, por não saber bem o que é e o que precisaremos enfrentar para alcançar o objetivo proposto; segundo, porque precisamos decidir o objeto de estudo, os autores, e, por último, mas não menos importante, é o desequilíbrio constante - sair da zona de conforto e provocar o nosso pensar de como estamos lendo os autores e as experiências?

Será simplesmente mais uma na área da alfabetização, que não contribui com a prática dos alfabetizadores? Como está o nosso olhar para este trabalho? É preciso, portanto, vincular o olhar do dia a dia, de alfabetizadoras, de formadoras, ao olhar de pesquisadoras na alfabetização. Sair da nossa escuta e desafiar-nos a escutar as teorias da alfabetização e do letramento e, também, as alfabetizadoras, de maneira a não neutralizar as ações desse processo. 
É nesse sentido que nos vemos construindo a metodologia, chamada Festa das Letras, criado pela doutora, Neli Gai, especialista em Alfabetização vemos que não é um risco harmonioso de um tricô em que cada ponto vai acrescentando a anteriores e á rede vai se ajustando. Há cortes dramáticos de lãs que, de repente se interrompem e o risco vai á outra direção. Diferentes mudanças de concepções, metodologias, métodos e técnicas que pareciam firmemente fundadas para produzir uma metodologia que possa contribuir, requer uma releitura com um olhar atento, ético e comprometido com os sujeitos envolvidos, com as produções da alfabetização e do letramento, no contexto local e amplo.

Um olhar desatento pode provocar leituras já realizadas e compreensões reducionistas que não contribuem com as reflexões necessárias para as questões da alfabetização e do letramento. Contudo, a formação que recebemos, na graduação e nos cursos de formação básica e continuada não nos possibilitava compreender porque as crianças são diferentes.

Instigava-nos a pergunta: como compreender teórica e metodologicamente para que todas as crianças sejam incluídas cognitivamente no processo da leitura e da escrita? Quais são os conhecimentos essenciais para o alfabetizador? É necessário um currículo didático para a alfabetização? Na busca de construirmos alternativas a essas inquietações, reorganizamos a prática e, consequentemente, a formação dos alfabetizadores.

Por meio desse estudo constante, com o objetivo de compreender como foram ensinadas as crianças, o que podemos aproveitar e o que devemos ressignificar, começamos um diálogo constante com os colegas das escolas e nos cursos de formação de alfabetizadores, os quais têm o compromisso e a responsabilidade de estudar os fatores da não aprendizagem das crianças.

A partir desses estudos, passamos a enxergar a sala de aula como uma "festa de diferenças", onde todos são capazes de aprender e se desenvolver, mas com o seu ritmo, em seu tempo, respeitando suas especificidades, sentimos aí uma vontade de contribuir com todos os níveis de aproveitamento: é desse ponto de vista teórico-metodológico que a compreensão e o trabalho com as diferenças individuais no processo ensino-aprendizagem da leitura e da escrita supõem atividades técnicas que permitam que todos os níveis evoluam em sua aprendizagem.

Implica em fazer um diagnóstico contínuo de aprendizagem, sem esperar a avaliação final do processo. A proposta requer incluir verdadeiramente todos no processo de aprendizagem a partir de momentos com atividades específicas para cada nível, possibilitando que comecem a realizar as atividades que possuem condições e mais gostam. Gradativamente, acrescentam-se atividades e temáticas que possibilitem o desenvolvimento integral.

Esses aspectos explicitam a importância da compreensão das condições essenciais para o próprio aprendizado. De acordo com o acima exposto, um dos requisitos mais importantes para o 
êxito do ensino, para a elevação da efetividade, é a atenção ao alfabetizado, às particularidades das crianças. Para muitos alfabetizadores, essa ação resulta em incompatibilidade com suas concepções do processo ensino-aprendizagem da leitura e da escrita, essa incompatibilidade foi construída historicamente pelos métodos homogêneos. Os efeitos sobre a desmotivação, devida as experiências negativas dos alfabetizadores e das próprias crianças, apresentam-se como argumentos contrários a esse tipo de trabalho por níveis de aproveitamento.

Aceitar que os alunos são diferentes uns dos outros é fácil. Difícil é tratar educativamente essas diferenças e ajudar para que elas enriqueçam o processo de ensino aprendizagem. Antes de tudo é uma questão de posicionamento filosófico, ético ou ideológico: até que ponto a equipe escolar está de acordo em aceitar que cada um dos alunos tem o direito a que o ensino se adapte o máximo possível a suas possibilidades e limitações? (ARAN, 2002, p. 11).

O processo da leitura e da escrita diferenciadas deve enfrentar o problema de base: como as crianças dos anos iniciais aprendem? Como criar uma relação menos utilitarista dos métodos de ler e de escrever e instaurar um processo ensino e aprendizagem que dê um verdadeiro sentido? Como inscrever o trabalho da leitura e da escrita em uma perspectiva social e em uma relação entre toda a comunidade escolar que façam da escola um local de inclusão cognitiva?

Quando nós assumimos como alfabetizadoras - pesquisadoras, a vontade de estar com as crianças é acentuada, pois vemos nelas uma fonte enriquecedora da nossa formação: a cada dia uma descoberta, uma possibilidade a mais para ensinar a leitura de mundo e a leitura da palavra, produzindo conhecimento.

Os diferentes níveis de aprendizagem das crianças, como diz soam como vozes que exigem mais atenção. Diante disso, nos perguntamos: é possível desaprender para aprender, aplicando uma alfabetização das diferenças, e ensinar a todos alcançarem os conhecimentos correspondentes aos seus limites, aos seus respectivos "mundos". Candau, contribui dizendo:

[...] que respeitavam o ritmo de cada aluno/a e mesmo, na modalidade de ensino programado ramificado, oferecia caminhos diferenciados, de acordo com respostas a cada unidade de aprendizagem proposta, para que cada um/a atingisse o comportamento final proposto. (CANDAU, 2011, p. 243).

Para isso acontecer, é necessário prestar mais atenção à idade com que estamos trabalhando, aos conhecimentos correspondentes à série, a um currículo didático - com metodologia, métodos, técnicas e estratégias adequadas ao alcance dos objetivos -; por isso a ideia de uma pesquisa constante. O nosso desejo de pensar que na formação das alfabetizadoras, elas sejam capazes de priorizar a alfabetização cognitiva, aproximamos os aspectos teóricos e aos metodológicos para assim fazer intervenção. Percebemos, no olhar das crianças, a necessidade de ser enxergadas por meio do 
currículo, do Projeto Político-Pedagógico e pelos planejamentos de ensino e de aprendizagem da alfabetização. Os distanciamentos entre a reflexão teórica e a metodológica sobre as ações das alfabetizadoras, mostram as fragilidades que hoje tomamos como um objeto de pesquisa na alfabetização, explicam nosso desejo pelo objeto de estudo e pela ideologia que seguirmos.

Desde a implantação do projeto, as acadêmicas dos cursos de Pedagogia participam de atividades de formação visando à construção dessa proposta. Preocupados com isso, o curso de Pedagogia desenvolveu na disciplina de alfabetização e letramento, uma nova estratégia para que as crianças aprendam a ler e escrever de forma lúdica, mas de cunho sistematizado e científico intitulado "festa das letras", esta prática, proporciona as crianças uma nova forma de aprender, de modo prazeroso e essencialmente lúdico.

A festa das letras apresenta metodologias diferenciadas para o processo de alfabetização, dentre elas: rimas, história da escrita, história do alfabeto, canto, além de um ambiente alfabetizador. Conta com estratégias diferenciadas, tanto para o alfabetizador ensinar, quanto para a criança com os diferentes níveis de aprendizagem aprender.

\section{CONSIDERAÇÕES FINAIS}

A socialização dessa experiência em várias escolas, construídas no âmbito do projeto, contribui para a construção do percurso formativo dos alfabetizadores, na medida em que visualizam e viabilizam importantes reflexões acerca da prática pedagógica do alfabetizador, considerando os aspectos científicos da alfabetização no mundo lúdico da criança.

Tendo sido aplicada com vários grupos de crianças, com idade entre 05 e 09 anos, a Festa das Letras, apresenta como resultados, práticas que podem certamente ser utilizadas na alfabetização com as crianças de todos os lugares, além de auxiliar na apropriação do processo de leitura e escrita, fatores indispensáveis para o desenvolvimento cognitivo e social das crianças.

O resultado dessa metodologia, Festa das letras, sugere a qualificação do processo formativo dos alfabetizadores. Conclusões Uma das recentes constatações é que os acadêmicos demonstram conhecimento técnico, pedagógico e desejo em alfabetizar.

Observa-se pelo depoimento das crianças: "Eu gostei da Festa das letras, estava bem colorido, as letras também eram coloridas, fiquei feliz porque ganhei um livrinho, uma bolacha e uma almofada com o meu nome para levar para casa. Gostei da caverna e das rimas, foi muito legal.” "Aprendi o alfabeto, dos homens das cavernas que eles escreviam nas paredes as palavras (história da escrita), dos desenhos que tinham letras, no desenho da cerca tinha o $\mathrm{H}$ (história do alfabeto), o som das letras também ( alfabeto fônico) e da moça surda que ensinou o alfabeto alfabeto das mãos (alfabeto em libras)." A alfabetização nunca esteve tão presente no contexto das discussões como 


\section{REFERENCIAS}

ÁVILA, IvanyS.Alfabetizador bemsucedido: um mito, uma realidade ou um universo relacional de significados? In:ANPEd, 1989.

ARENA, Dago berto B. Supervisore alfabetizador: novas concepções para nova prática.1991.

ARAN, Artur Parcerisa. In: Introdução. In: SACRISTÁN, José Gimeno; ALCUDIA, Rosa; DEL CARMEN, Marisa. et al. Atenção à diversidade. Artmed: Porto Alegre, 2002. p. 11-12.

CANDAU, Vera Maria Ferrão. Diferenças culturais, cotidiano escolar e práticas pedagógicas. Currículo sem Fronteiras, v.11, n.2, pp.240-255, Jul/Dez 2011. Disponível em: > http://www.curriculosemfronteiras.org/vol11iss2articles/candau.pdf> Acesso em 18 out. 2015.

SOARES, Magda.AlfabetizaçãonoBrasil:oestadodoconhecimento.Brasília: INEP/REDUC, 1989.

;MACIEL, Francisca.Alfabetização. Brasília: MEC/INEP/

Comped,2000.

.Letramento e alfabetização: as muitas facetas. Revista Brasileira de Educação, n.25,p.5-17, jan./abr.2004. p. 61-125. 